\title{
Numerical Simulation and Its Application on Deformation and Stress Distribution of Coal Body Around Spraying Hole Induced by Waterpower
}

\author{
Yun Baoju, Liu Jianzhuang \\ College of Mining Engineering \\ Hebei United University \\ Tangshan, China \\ cumtljz@163.com
}

\author{
Cheng Yuanping \\ Faculty of Safety Engineering \\ China University of Mining and Technology \\ Xuzhou,China;
}

\begin{abstract}
As a widely used finite difference software in coal mine research, FLAC3D is applied with to simulate the deforming course of coal body around spraying hole induced by waterpower. The results are appealing and instructive for optimization of gas drainage holes in outburst mine. Two core simulating distribution rules on stress field and displacement field issued in this paper are both verified on site in Qinan Coal Mine of Huaibei Group. The methane drainage monitoring data indicate that spraying hole through beds induced by waterpower is beneficial to improve the drainage effect. Therefore, the paper provides technicians on gas comprehensive control with new bases and practical reference.
\end{abstract}

Keywords-Outburst coal seam, Hole spraying, Numerical simulation, engineering application

\section{INTRODUCTION}

With the help of Hydraulic pressure, the gas drainage hole can be induced to spray in outburst coal seam[1-4]. Loaded by ground stress the coal body controled by measure holes suffur from deformation, rheology, cracking order by order. The fracture net will form after they opens and coalescences. In doing so, the methane permeability of the body is improved and its gas drainage flow increases. Consequently, the rock mass mechanics research is significant for coal-AR, optimal holes placement, improving drainage efficiency, shartening outburst control measure applying time, etc.

\section{Flac3D Model Construction And Simulating}

\section{A. $\quad$ Model simplifying and designing}

As soon as the through coal holes sprays in outburst seam, the surrounding coal body will suffur rheology, movement and deformation in the direction of the spraying holes, and then fill them. Therefore, the stress distribution around them will change. FLAC3D is a three-dimensional explicit finitedifference program for engineering mechanics computation, widely used in geotechnics, mining technology, tunnuel technology, etc[5]. In our 3D model, we simplying the whole body to three seams, the upper roof strata, the middle coal seam, the lower floor strata. Their inclination angle is zero. That is, they are horizontally disposed in the model. The hole is simulated by an proportional cylinder in diameter and height, which will be excavated by the FLAC order of model null. The rock mechanical parameters are shown in Table 1.

\section{B. Size and boundry constraints of the model}

Based on the theoretical analysis, we set the simulating hole's diameter to be 4 meters, which is in accordance with our on-site observation in coal mines of Huaibei Group. The length of the model is 40.0 metres. According to Qinan Coal Mine, the coal seam's thick is set 2.0 metres, the others are both 15.0 metres. So our FLAC3D model is established with 40 meters length, 40 meters width, and 32 meters height, whose quarter part is shown in Fig. 1. In the model, the whole range of $\mathrm{X}$ coordinate and $\mathrm{Y}$ coordinate is -20 to 20 , that of $\mathrm{Z}$ coordinate -16 to 16 . Given the computer's arithmetic capability and the research problem's precision need, we plot the model cell 62400 zones and 67229 gridpoints. Based on the actual loading case, the boundry conditions are set: bottom boundary's vertical displacement confined, the four vertical boundaries' horizontal diaplacement confined.

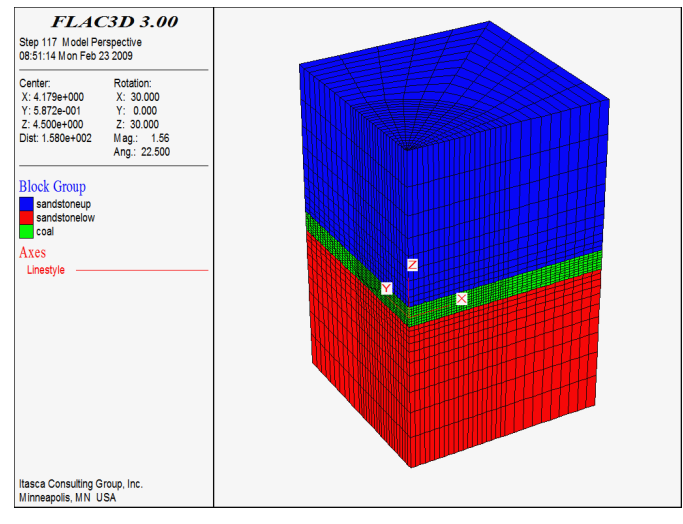

Figure 1. Quarter of FLAC3D model

\section{Simulating Results}

\section{A. Stress distribution}

The model is initially loaded in the five faces except the bottom by three uniform pressure, 15.0MPa. After step to balance state, the hole with 2 metres diameter and 2 metres height, is trenched by the order model null. Therefore, a new balance will be get to simulate the drilling. In computing, we record five points stress change vs steps, whose ordinates are $(2,0,0),(3,0,0),(4,0,0),(6,0,0)$, and $(8,0,0)$. The histrory results are shown in Fig.2. 

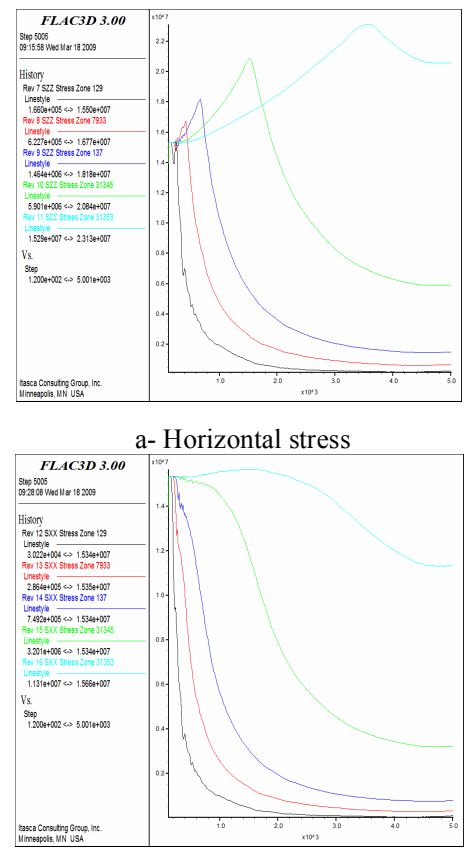

b- Vertical stress

Figure 2. History stress on five points vs step

As indicated in Fig.2, zones should experience four phases respectively characterized with initial stress load, concentration stress load, peak stress load, and residual stress load. In early hole spraying stage, zones suffer with initial rock stress. Then with the drilling developing, they are gradually loaded additional stress. The surrounding zones relieve pressure surpass their ultimate bearing capacity by yielding. Closer zones do more pressure in the stress adjustment procedure, and vice versa. Fig. 3 shows the stress distribution in the balance model at the face $\mathrm{Z}=0$. Obviously, there are three ranges around the hole, which could be called stress-relaxation zone, stress-increase zone, and stress-initial balance zone. In the figure, also we can see the circular isoline for horizontal stress and elliptical isoline for vertical stress. The vertical concentrating stress is bigger than the horizontal ones.

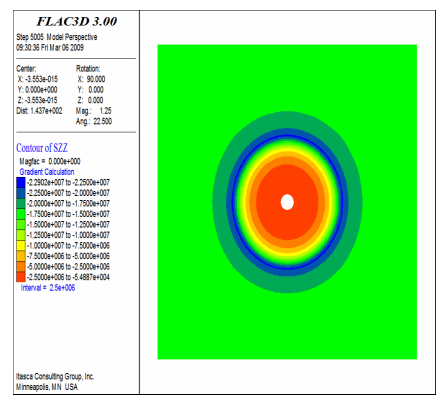

a- Horizontal stress

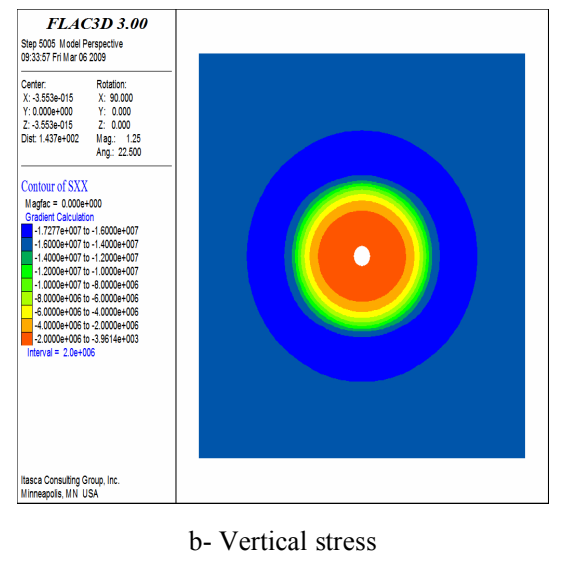

Figure 3. Stress distribution at the face $\mathrm{Z}=0$

\section{B. Displacement distribution}

The five points' displacement are also monitored in computing. The history curves all has bigger slope on two borders than in the middle, as shown in Fig. 4. The mechanical reason can be illustrated as followed: firstly, the displacement changes with low speed. Secondly, big concentrated stress loads on the surounding zones, which is followed by zone plastic yielding, cracks forming, volume expansion. The process is associated with rapid increasing displacement. Finally, yielding zones under peak stress are destoried and realize unloading, with the flat displacement curve.

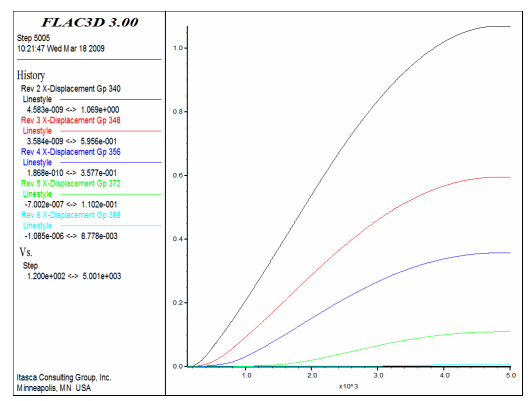

Figure 4. Displacements of the five key points

(hole's radius being1.0 metre)

Figure. 5 illustrates the radical displacement distribution around the hole. It changes speedy from 226 centimeters on the boundary to 60 centimeters on the 3 meters depth zones. The range from 3.0 to 7.8 meters distance to the hole can be called elaxation district, because of the flat displacement change. The displacement on the peak stress zones is centimeter. The outer zones' displacement tends to zero gradually. Therefore, the effectual district can be thought in the range from boundry of the hole to the peak stress point. 


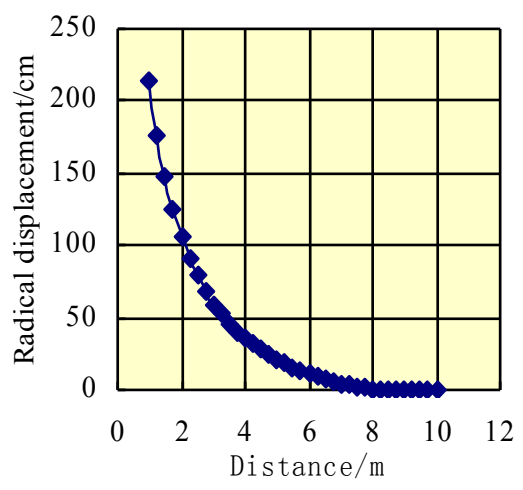

Figure 5. Radical displacement around spraying hole

\section{ENGINEERING APPLICATION}

\section{A. General situation of Qinan Coal Mine}

Belong to Huaibei Group, Qinan Coal Mine's production capacity is about 2.4 million tons per year. The main mineable coal seam is $7 \#$ seam with the thick of 2.64 metres. The gas pressure is measured to be $3.5 \mathrm{MPa}$, gas content 12.29 15.38 m3/t, and the original gas permeability coefficient $0.046 \mathrm{~m} 2 /(\mathrm{MPa} 2 . \mathrm{d})$. The results above goes to show us 7\# coal seam characterized with low air permeability, high risk of outburst. In the mine history of the mine, underlying strata and gas outburst has occurred, also coal outburst and postpone outburst does.

In order to guarantee safe mining, we arrange through beds holes from floor roadway and bedding holes in the seam to drainage methane, which is called regional gas control mode in China.

\section{B. Design of the drainage holes}

Based on the stress and displacement simulating results above metioned, we lay the floor drainage roadway with 25 metres distance to the sheltered roadway in the coal seam. The horizontal distance of the two roadways is also 25 metres. There are some drilling fields in the floor roadway with 25 metres spacing. More details can be seen in Fig. 6.

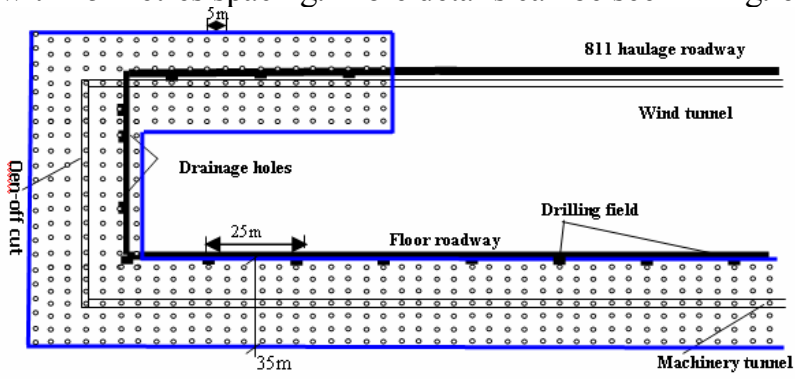

Figure 6. Face 713 drilling engineering planar graph

\section{Effects of outburst control measures}

After drilling the holes, we apply $5 \mathrm{MPa}$ pressure hydraulic water to induce hole spraying. According to our statistic, every firstly completed holes in the drilling fields has spraied, about three to five spraying holes in one fields. There are detail data in Table 2.

Fig. 7 shows the methane drainage volume for 700 days. It indicates the average mixing flux is $20.7 \mathrm{~m} 3 / \mathrm{min}$, realtime flux adjusting in the range of $5.02 \sim 35.14 \mathrm{~m} 3 / \mathrm{min}$. The symmetric numbers of pure methane flux are $2.6 \mathrm{~m} 3 / \mathrm{min}$ and $0.15 \sim 4.7 \mathrm{~m} 3 / \mathrm{min}$. We have drainaged about 1.7005 million $\mathrm{m} 3$ accumulated mix methane from the floor roadway. In the end, the gas extraction efficiency has come to be $63.4 \%$, and the average residual methane content to be under $4.5 \mathrm{~m} 3 / \mathrm{t}$. From the above indicates about outburst control measures, it appears that the holes design in Qinan Mine is reasonable and efficient.

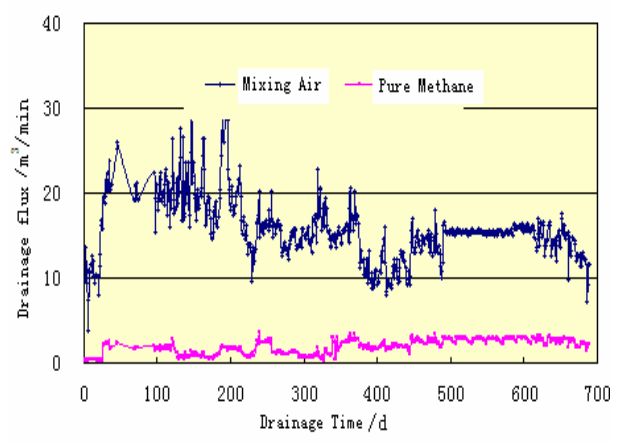

Figure 7. Face 713 drainage flux changes

\section{CONCLUSIONS}

(1)FLAC3D simulating results on rock mechanism surrounding holes are instructive to design outburst control holes.

(2)Hydraulic induced spraying hole is an effective measure for improving methane permeability in outburst coal seam.

(3)Methane can be drainaged from the coal body after the holes' spraying. The lows are more spraying coal, more methane. Therefore, the outburst coal seam can be mined safely under reasonable measures.

\section{REFERENCES}

[1]

[2] G. Eason, B. Noble, and I. N. Sneddon, "On certain integrals of Lipschitz-Hankel type involving products of Bessel functions," Phil. Trans. Roy. Soc. London, vol. A247, pp. 529-551, April 1955. (references)

[3] J. Clerk Maxwell, A Treatise on Electricity and Magnetism, 3rd ed., vol. 2. Oxford: Clarendon, 1892, pp.68-73.

[4] I. S. Jacobs and C. P. Bean, "Fine particles, thin films and exchange anisotropy," in Magnetism, vol. III, G. T. Rado and H. Suhl, Eds. New York: Academic, 1963, pp. 271-350.

[5] K. Elissa, "Title of paper if known," unpublished.

[6] R. Nicole, "Title of paper with only first word capitalized," J. Name Stand. Abbrev., in press.

[7] Y. Yorozu, M. Hirano, K. Oka, and Y. Tagawa, "Electron spectroscopy studies on magneto-optical media and plastic substrate interface,” IEEE Transl. J. Magn. Japan, vol. 2, pp. 740-741, August 1987 [Digests 9th Annual Conf. Magnetics Japan, p. 301, 1982].

[8] M. Young, The Technical Writer's Handbook. Mill Valley, CA: University Science, 1989. 
[9] Electronic Publication: Digital Object Identifiers (DOIs):

Article in a journal:

[10] D. Kornack and P. Rakic, "Cell Proliferation without Neurogenesis in Adult Primate Neocortex," Science, vol. 294, Dec. 2001, pp. 21272130, doi:10.1126/science.1065467.
Article in a conference proceedings:

[11] H. Goto, Y. Hasegawa, and M. Tanaka, "Efficient Scheduling Focusing on the Duality of MPL Representatives," Proc. IEEE Symp. Computational Intelligence in Scheduling (SCIS 07), IEEE Press, Dec. 2007, pp. 57-64, doi:10.1109/SCIS.2007.357670.

TABLE I. HOLES PARAMETERS COMPARISON BEFORE AND AFTER SPRAYING

\begin{tabular}{|c|c|c|c|c|c|c|c|}
\hline $\begin{array}{c}\text { Drilling field } \\
\text { number }\end{array}$ & $\begin{array}{c}\text { Whole length } \\
\text { /m }\end{array}$ & $\begin{array}{c}\text { Length in rock } \\
\text { /m }\end{array}$ & $\begin{array}{c}\text { Length in coal } \\
\text { /m }\end{array}$ & $\begin{array}{c}\text { Spraying volume } \\
\text { /m3 }\end{array}$ & $\begin{array}{c}\text { Applying diameter } \\
\text { /mm }\end{array}$ & $\begin{array}{c}\text { Diameter after } \\
\text { spraying } \\
\text { /mm }\end{array}$ & $\begin{array}{c}\text { Diameter expanding } \\
\text { times in coal }\end{array}$ \\
\hline $1 \#$ & 1312 & 1173 & 139 & 9.43 & 94 & 257.84 & 2.74 \\
\hline $2 \#$ & 1345 & 1215 & 130 & 5.22 & 94 & 198.36 & \\
\hline $3 \#$ & 1327 & 1192 & 135 & 5.81 & 94 & 202.82 & 2.11 \\
\hline $4 \#$ & 1365 & 1225 & 140 & 10.45 & 94 & 283.10 & \\
\hline $5 \#$ & 1344 & 1209 & 135 & 7.47 & 94 & 232.86 & 3.01 \\
\hline $6 \#$ & 1328 & 1200 & 128 & 9.21 & 94 & 265.53 & 2.48 \\
\hline $7 \#$ & 1353 & 1213 & 140 & 6.23 & 94 & 208.82 & 2.82 \\
\hline
\end{tabular}

TABLE II. PHYSICAL AND MECHANICAL PROPERTY PARAMETERS OF THE THREE ROCK SEAMS

\begin{tabular}{|l|c|c|c|c|c|c|}
\hline Lithology & $\begin{array}{l}\text { Young's } \\
\text { modulus } \\
\text { /GPa }\end{array}$ & $\begin{array}{l}\text { Poisson's } \\
\text { ratio }\end{array}$ & $\begin{array}{l}\text { Friction } \\
\text { angle } \\
\text { /0 }\end{array}$ & $\begin{array}{l}\text { Tensile } \\
\text { strength } \\
\text { /MPa }\end{array}$ & $\begin{array}{l}\text { Density } \\
\text { /kg.m- } \\
\mathbf{3}\end{array}$ & $\begin{array}{l}\text { Thickness } \\
\text { /m }\end{array}$ \\
\hline $\begin{array}{l}\text { Upper and } \\
\text { lower:Sandy } \\
\text { Mudstone }\end{array}$ & 27.0 & 0.4 & 30 & 1.0 & 2200 & 15 \\
\hline Middle:Coal & 0.71 & 0.3 & 17 & 0.8 & 1400 & 2 \\
\hline
\end{tabular}

